\title{
Impact of reduced exposure to calcineurin inhibitors on the development of de novo DSA: a cohort of non-immunized first kidney graft recipients between 2007 and 2014
}

S. Girerd ${ }^{1,2^{*}}$, J. Schikowski ${ }^{1}$, N. Girerd ${ }^{2}$, K. Duarte ${ }^{2}$, H. Busby ${ }^{3}$, N. Gambier ${ }^{4}$, M. Ladrière ${ }^{1}$, M. Kessler ${ }^{1}$, L. Frimat ${ }^{1}$ and A. Aarnink ${ }^{5}$

\begin{abstract}
Background: In low-immunological risk kidney transplant recipients (KTRs), reduced exposure to calcineurin inhibitor (CNI) appears particularly attractive for avoiding adverse events, but may increase the risk of developing de novo Donor Specific Antibodies (dnDSA).

Methods: $\mathrm{CNI}$ exposure was retrospectively analyzed in 247 non-HLA immunized first KTRs by taking into account trough levels (CO) collected during follow-up. Reduced exposure to CNI was defined as follows: C0 less than the lower limit of the international targets for $\geq 50 \%$ of follow-up.

Results: During a mean follow-up of $5.0 \pm 2.0$ years, 39 patients (15.8\%) developed dnDSA (MFI $\geq 1000)$. Patients with DSA were significantly younger (46.6 \pm 13.8 vs. $51.7 \pm 14.0$ years, $p=0.039$ ), received more frequently poorlymatched grafts (59\% with 6-8 A-B-DR-DQ HLA mismatches vs. 34.6\%, $p=0.016$ ) and had more frequently a reduced exposure to $\mathrm{CNI}(92.3 \%$ vs. $62.0 \%, p=0.0002)$. Reduced exposure to $\mathrm{CNI}$ was associated with an increased risk of dnDSA (multivariable HR=9.77, $p=0.002$ ). Reduced exposure to CNI had no effect on patient survival, graft loss from any cause including death, or post-transplant cancer.
\end{abstract}

Conclusions: Even in a low-immunological risk population, reduced exposure to CNI is associated with increased risk of dnDSA. Benefits and risks of under-immunosuppression must be carefully evaluated before deciding on CNI minimization.

Keywords: Kidney transplantation, Calcineurin inhibitors, Donor specific antibodies, Under immunosuppression

\section{Background}

Calcineurin inhibitors $(\mathrm{CNI})$ were first introduced in the 1980s and have led to dramatic improvements in short-term kidney transplantation outcomes. Nevertheless, $\mathrm{CNI}$ were traditionally thought to be the major contributors of chronic kidney graft dysfunction due to nephrotoxicity [1]. This historical view was challenged during the past decades [2, 3], given that chronic graft nephropathy was largely related to humoral chronic rejection [4-6] and not only CNI nephrotoxicity [7].

\footnotetext{
* Correspondence: s.girerd@chru-nancy.fr

'Service de Néphrologie et Transplantation rénale, CHRU Nancy Brabois, Vandoeuvre-les-, Nancy, France

2INSERM, Centre d'Investigations Cliniques Plurithématique 1433, Université de Lorraine, CHRU de Nancy and F-CRIN INI-CRCT, Nancy, France Full list of author information is available at the end of the article
}

Nevertheless, the overall level of immunosuppressive therapy obviously increases the risk of infectious or neoplastic complications [8]. Therefore, clinicians continue to attempt numerous protocols to reduce exposure to $\mathrm{CNI}$, including primary avoidance, dose reduction, and switching to other drug classes, namely mTOR inhibitors or belatacept [9-12].

There is now a large body of evidence whereby antibody-mediated rejection (ABMR) is the major cause of late kidney allograft failure [4-6]. CNI minimization may fail to improve long-term outcomes due to the development of Donor Specific Antibodies (DSA) and chronic rejection despite less chronic nephrotoxicity. Thus, nephrotoxicity prevention by CNI minimization may be counterbalanced by an increased risk of DSA development, leading to

(C) The Author(s). 2018 Open Access This article is distributed under the terms of the Creative Commons Attribution 4.0 International License (http://creativecommons.org/licenses/by/4.0/), which permits unrestricted use, distribution, and 
non-significant improvements in long-term graft prognosis. In low immunological risk populations, the impact of reduced exposure to $\mathrm{CNI}$ is of particular interest, considering that the benefit/risk balance is, a priori, in disfavor of strong immunosuppressive therapy.

The present study aimed to assess the impact of reduced exposure to CNI (i.e. CNI trough level reduction without avoidance or switch) on the development of de novo DSA (dnDSA) among a cohort of low-immunological risk patients, i.e. first kidney transplant recipients (KTRs) with negative class I and class II anti-HLA antibodies prior to transplantation.

\section{Methods}

\section{Study population}

This observational single-center cohort study included all non-immunized first KTRs in the University Hospital of Nancy between 01/01/2007 and 31/12/2014. Exclusion criteria consisted of patients aged $<18$ years, receiving a combined non-renal graft, or followed in another center after the transplantation. Patients who did not receive CNI or had CNI discontinuation during follow-up were also excluded. Patients with more than $50 \%$ of missing values of CNI trough levels $(n=7)$ were also excluded. The study population flowchart is presented in Fig. 1. Non-immunization was defined by the absence of both class I and class II anti-HLA antibodies before transplantation as assessed by Luminex technique, as described hereafter.

Immunosuppressive therapy consisted in an induction therapy (anti-thymocyte globulins or anti-IL2 monoclonal antibody), steroid pulses, followed by maintenance therapy generally including long-term oral corticotherapy ( $5 \mathrm{mg} /$ day), an antimetabolite (mycophenolic acid or azathioprine) and CNI (either tacrolimus or cyclosporine). The usual initial dosage of tacrolimus was $0.15 \mathrm{mg} /$ $\mathrm{kg} /$ day for tacrolimus and $6 \mathrm{mg} / \mathrm{kg} /$ day for cyclosporine. The initial dosage of mycophenolic acid was $1000 \mathrm{mg} /$ day when associated with tacrolimus and $2000 \mathrm{mg} /$ day when associated with cyclosporine.

\section{Data collection}

Data were extracted from the prospective French database of transplanted patients DIVAT (computerized and VAlidated data in Transplantation) (www.divat.fr). Written informed consent was obtained from all participants and The "Comité National de l'Informatique et des Libertés" approved the study (CNIL no. 891735). Data were entered in a computerized database on day 0 , at 3 months and 12 months, and subsequently updated annually thereafter. Patients were followed annually until June 2016.

Characteristics collected at baseline included: age, gender, body mass index, comorbidities, causal nephropathy, dialysis method and time on dialysis prior to kidney transplantation, as well as duration on waiting list. Transplantation

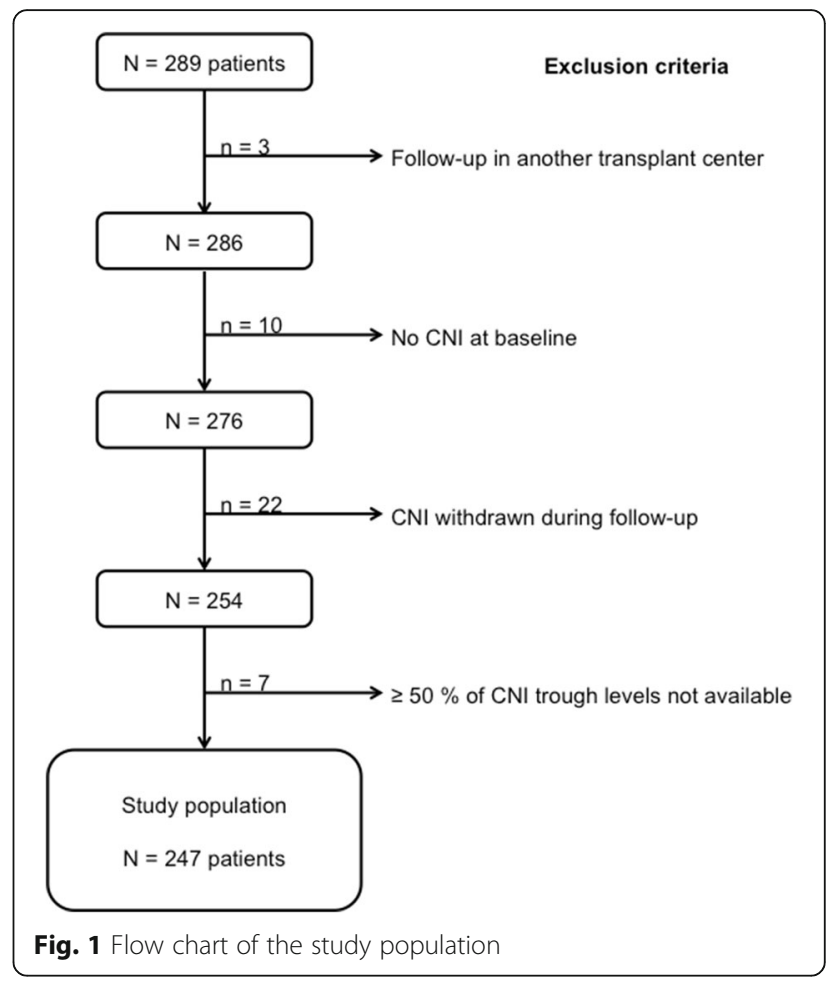

parameters included: donor type (living donors; standard criteria donors (SCD); expanded criteria donors (ECD) defined as follows: donors aged $\geq 60$ years, or donors aged $50-59$ years with $\geq 2$ of the following conditions: history of hypertension, cerebrovascular cause of death, serum creatinine greater than $1.5 \mathrm{mg} / \mathrm{dL}$ ), cold ischemia time, HLA A-B-DR-DQ incompatibilities, induction therapy and maintenance immunosuppressive regimen, as well as delayed graft function defined by the necessity of one or more dialysis sessions in the first week after transplantation. Data collected during follow-up included: dnDSA detection, acute rejection, return to dialysis and death before return to dialysis. Post-transplant cancers were also recorded. Patients were followed until death, return to dialysis or last follow-up visit up until March 2016. Mean follow-up was $5.0 \pm 2.0$ years.

\section{Anti-HLA immunization and DSA detection}

All patients included in the study cohort underwent a search for anti-HLA class I and class II antibodies that was negative prior to transplantation. The monitoring of anti-HLA immunization after transplantation was performed at 3, 6 and 12 months after the graft and annually thereafter, as well as at the time of biopsy when clinically warranted (presence of graft dysfunction or suspicion of rejection). The sera were screened for HLA-specific antibodies using solid-phase Luminex HLA antibody-detection beads (LABScreen $^{\mathrm{Tm}}$ Mixed, One Lambda Inc., Canoga Park) and selected HLA-specific antibody-positive samples 
were analyzed using Luminex single-antigen HLA class I and class II antibody-detection beads (LABScreen ${ }^{\text {Th }}$ Single Antigen HLA Class I and Class II, One Lambda Inc., Canoga Park). Antibodies were considered as Donor Specific Antibodies if the MFI (Mean Fluorescence Intensity) of antibodies directed against a donor antigen (HLA-A, -B, -C, -DR, -DR51, -DR52, -DR53, -DQ or -DP) was greater than 1000. For each serum, the sum of MFI DSA(s) was also studied. In instances where the recipient had DSA directed against a homozygous donor antigen, the MFI was doubled.

\section{Exposure to $\mathrm{CNI}$}

The blood concentration of CNI were measured by the antibody-conjugated magnetic immunoassay (ACMIA) method using an Dimension ${ }^{\bullet}$ system (Siemens). The lower limit of quantification was $25 \mathrm{ng} /$ $\mathrm{mL}$ and $2 \mathrm{ng} / \mathrm{mL}$ for cyclosporine and tacrolimus, respectively. Trough levels were measured at month 3, month 6, month 12, and annually thereafter. For every patient and every outcome, the number of time intervals of CNI exposure before the event was established considering that the event itself could lead to a modification in CNI posology (the next trough level may be the consequence of the event). For example, in the case of first DSA detection at month 30 (Fig. 2), the time intervals M0-M3 (trough level measured at month 3), M3-M6 (trough level measured at month 6), M6-M12 (trough level measured at month 12) and M12-M24 (trough level measured at month 24) were taken into account.
Trough levels less than the lower limit of the international targets [13-15] for $\geq 50 \%$ of time intervals defined the reduced exposure to CNI. In case of a missing value, the time interval was not considered, and the total number of intervals decreased accordingly.

\begin{tabular}{lll}
\hline Post transplant delay & $\begin{array}{l}\text { Cyclosporine trough } \\
\text { level }(\mathrm{ng} / \mathrm{mL})\end{array}$ & $\begin{array}{l}\text { Tacrolimus trough } \\
\text { level }(\mathrm{ng} / \mathrm{mL})\end{array}$ \\
\hline $0-3$ months & $250-350$ & $10-15$ \\
$3-6$ months & $150-250$ & $8-10$ \\
$6-12$ months & $125-200$ & $6-8$ \\
$>12$ months & $100-150$ & $5-8$ \\
\hline
\end{tabular}

Consequently, patients were classified into two groups according to the presence or the absence of a reduced exposure to CNI. Patients having developed dnDSA or not during follow-up were also compared.

The distribution of CNI trough levels at each visit is presented in Fig. $3 \mathrm{a}$-d. The number of patients recieving tacrolimus increased over time while the number of patients receiving cyclosporin decreased, because some patients were switched from cyclosporin to tacrolimus during follow-up (Fig. 3).

\section{Statistical methods}

All analyses were performed using $\mathrm{R}$ software (the R foundation for Statistical Computing). The two-tailed significance level was set at $p<0.05$. Continuous variables are described as means \pm standard deviation, categorical

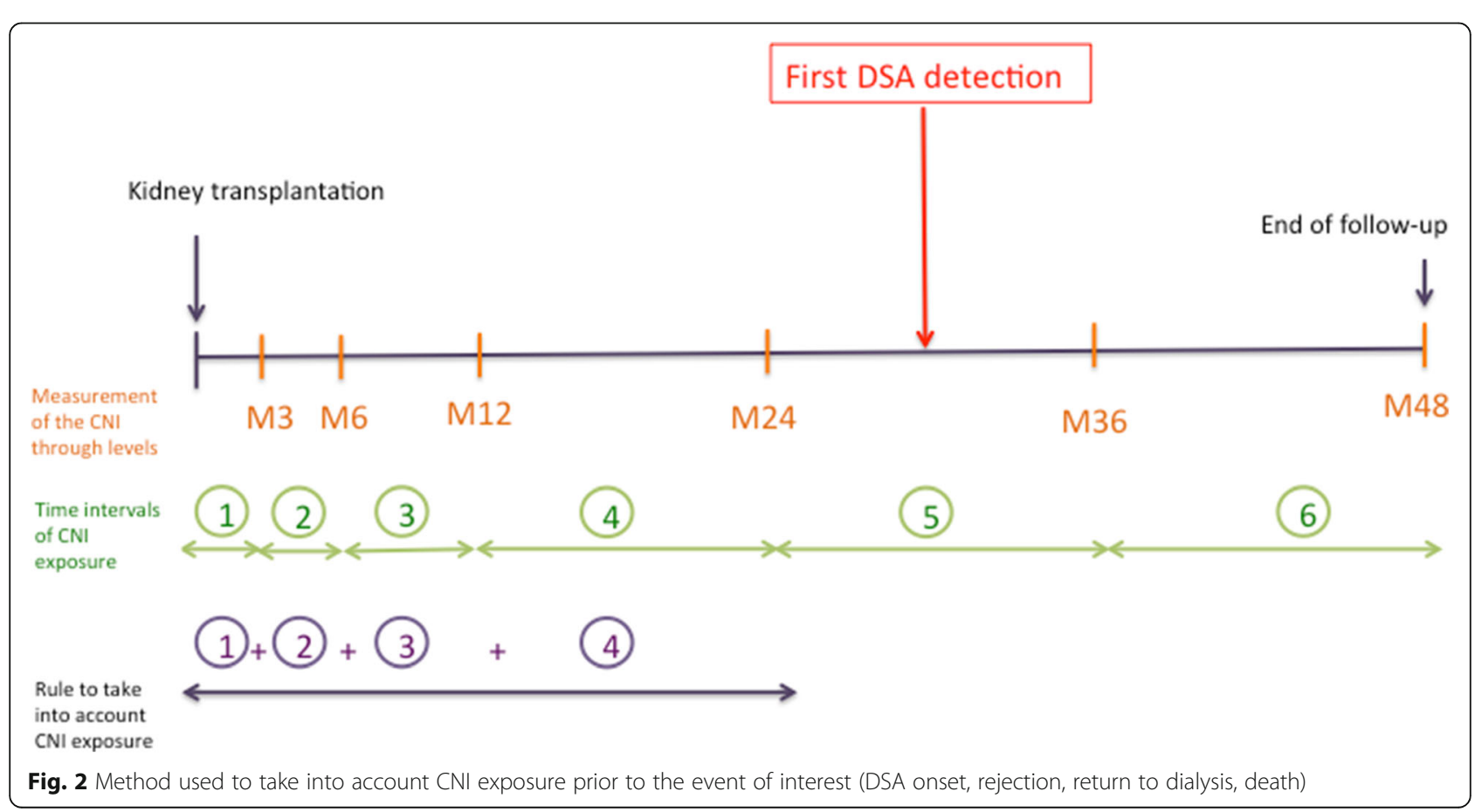




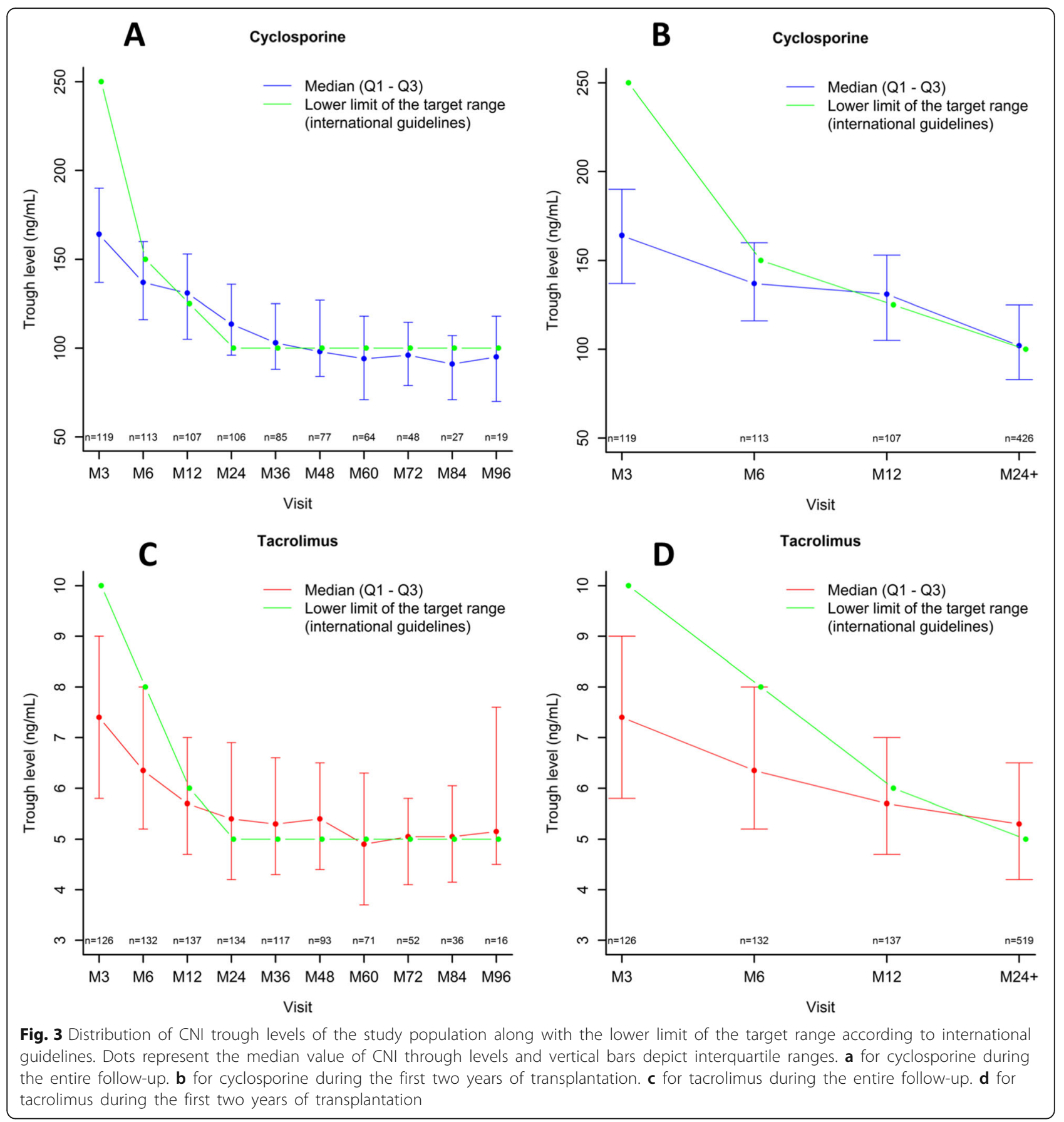

variables as frequencies (percentages). Hazard ratios are presented with their 95\% confidence intervals as HR (CI 95\%). Comparisons of baseline characteristics according to reduced exposure to CNI or not or DSA detection were carried out using the non parametric Mann-Whitney test for continuous variables and chi-square or Fisher's exact test for categorical variables. Time-to-event analyses using Cox regression models were performed to assess the associations between reduced exposure to $\mathrm{CNI}$ and outcomes (DSA detection, return to dialysis, death before return to dialysis, return to dialysis or death before return to dialysis). Proportional hazard assumption was thoroughly verified using the Schoenfeld residuals test. Multivariable analyses were performed using iterative backward selection $(p<0.05)$, by forcing "reduced exposure to CNI" in the Cox model, with the following variables as candidate covariates: number of HLA mismatches, donor type, age and gender of the recipient, mycofenolic acid cessation, delayed graft function and induction therapy. Survival rates are illustrated using Kaplan Meier analyses. 
Differences between survival curves were analyzed using the log-rank test. Intra-patient variability (IPV) of CNI trough levels was calculated. As others [16], C0 blood levels of cyclosporine to $\mathrm{C} 0$ tacrolimus equivalents were converted using an empiric $1 / 20$ correction factor, based on the limits of the international targets.

Intra-patient variability (IPV) in CNI exposure was also studied and defined as the fluctuation in CNI blood concentrations within an individual over a given period. The mean absolute deviation percent (MAD\%) formula was used as previously described [17]:

$$
M A D \%=\frac{1}{n} \sum \frac{a b s(X j-\bar{X})}{\bar{X}} * 100 .
$$

where:

- $\bar{X}$ represents the average of all available samples (in the case of tacrolimus IPV, the average of all tacrolimus trough levels measured for time period $j$ ), $\mathrm{X}_{\mathrm{j}}$ represents an individual data point (a single tacrolimus trough level measurement) and $\mathrm{n}$ the number of all available data points (the total number of all available tacrolimus trough levels during period $\mathrm{j}$ )

- Abs (...) denotes the absolute value function, such that the quantitative value $a b s(X j-\bar{X})$ is always a non-negative value. The obtained tacrolimus trough level $(\mathrm{C} 0)$ must be corrected to the corresponding daily tacrolimus dose (C0/D)

\section{Results}

\section{Baseline characteristics of the entire population}

A total of 247 KTRs were included. Mean age of graft recipients was $50.9 \pm 14.1$ years. The proportion of living donors was $27.5 \%$ while $15.4 \%$ of patients received preemptive kidney transplantation. With regard to HLA compatibility, $24.7 \%$ patients had $0-3$ mismatches (A-B-DR-DQ), 36.8\% had 4-5 mismatches and 38.5\% had 6-8 mismatches. An induction treatment was administered in $95.1 \%$ of patients (70.2\% with lymphocyte-depletive agent and $29.8 \%$ with anti-interleukin-2 receptor antibodies), while $49.0 \%$ received cyclosporine as maintenance therapy with the remaining $51.0 \%$ receiving tacrolimus. Other baseline data are provided in Table 1.

\section{Baseline characteristics of patients according to "exposure to CNI" status}

Patient characteristics according to the presence or the absence of a reduced exposure to CNI are presented in Table 1. Patients did not differ in terms of age, causal nephropathy or medical history (cancer or infectious disease prior to transplantation as well as cardiovascular history). Of note, the proportion of living donors and the proportion of expanded criteria donors were higher in the group with reduced exposure to CNI (respectively $33.3 \%$ vs. 15.9 and $27.9 \%$ vs. $20.7 \%, p=0.0008$ ). Moreover, the number of HLA A-B-DR-DQ incompatibilities differed according to the two groups with a higher proportion of very well matched patients as well as very poorly matched patients in the group with reduced exposure to CNI $(26.7 \%$ vs. 20.7 and $41.8 \%$ vs. $31.7 \%, p=$ 0.048 for $0-3$ mismatches and 6-8 mismatches, respectively). The proportion of induction treatment was similar in the two groups, as well as the proportion of mycofenolic acid cessation during follow-up. The proportion of patients with high CNI IPV was similar in the two groups (for IPV > 30\%: $12.1 \%$ vs. $14.6 \%, p=0.58$ ).

\section{Follow-up data: DSA detection and impact of reduced exposure to CNI on DSA appearance}

During follow-up, 39 patients (15.8\%) developed dnDSA (with MFI 21000). The proportion of KTRs who developed DSA during follow-up was higher in the group of patients with reduced exposure to CNI $(21.1 \%$ (35/166) vs $2.5 \%(2 / 81), p<0.0001)$ (Fig. 4). Patients who developed dnDSA were significantly younger $(46.6 \pm 13.8$ vs. $51.7 \pm$ 14.0, $p=0.039$ ) (Table 2), received more frequently poorly-matched grafts (59\% with 6-8 HLA mismatches in the group with DSA vs. $34.6 \%$ in the group without DSA, $p=0.016$ ), and have more frequently a reduced exposure to CNI (92.3\% vs. $62.0 \%, p=0.0002)$. The proportion of induction therapy was similar in both groups, as well as mycofenolic acid cessation during follow-up, or IPV. Of note, no patient had mycofenolic acid cessation before the first DSA detection in the group with DSA (Table 2). In a multivariate analysis adjusted for the number of HLA mismatches, donor type, age and gender of the recipient, mycofenolic acid cessation, delayed graft function and induction therapy, reduced exposure to CNI was associated with an increased risk of DSA development (for first detection of one DSA with MFI $>1000$, HR in multivariable analysis 9.77 (2.34-40.77), $p=0.002$; for first detection of DSAs with total MFI (sum MFI) $>6000 \mathrm{HR}=12.02(1.62-$ $89.25), p=0.015$ ) (Table 3). When adjusting, as a sensitivity analysis, on number HLA mismatches, donor type and induction treatment (without iterative backward selection) we found similar results (data not shown). When adjusting, as a sensitivity analysis, on number HLA mismatches, donor type and induction treatment (without iterative backward selection) we found similar results (data not shown). In addition, when adjusting on body mass index and cold ischemia time (without selection, based on the univariable analysis) we found similar associations and $p$-values (data not shown).

Only 3 ABMR were diagnosed during follow-up. A reduced exposure to CNI tended to be associated with an increased risk of all-type graft rejections $(\mathrm{HR}=5.65$ (0.73-43.74), $p=0.097)$. 
Table 1 Baseline and follow-up data of patients according to the absence or presence of a reduced exposure to CNI

\begin{tabular}{|c|c|c|c|c|}
\hline & Total $(n=247)$ & Controls $(n=82)$ & Reduced exposure to CNI $(n=165)$ & $p$-value \\
\hline \multicolumn{5}{|l|}{ DEMOGRAPHICS } \\
\hline Age (years) & $50.9 \pm 14.1$ & $51.1 \pm 13.1$ & $50.8 \pm 14.6$ & 0.91 \\
\hline Male (n, \%) & $173(70.0 \%)$ & $62(75.6 \%)$ & $111(67.3 \%)$ & 0.18 \\
\hline $\mathrm{BMI}\left(\mathrm{kg} / \mathrm{m}^{2}\right)$ & $25.5 \pm 4.8$ & $26.2 \pm 4.3$ & $25.1 \pm 4.9$ & 0.026 \\
\hline \multicolumn{5}{|l|}{ COMORBIDITIES } \\
\hline Hypertension (n, \%) & $235(95.1 \%)$ & 77 (93.9\%) & $158(95.8 \%)$ & 0.54 \\
\hline No smoker (n, \%) & $122(49.4 \%)$ & $44(53.7 \%)$ & $78(47.3 \%)$ & \\
\hline Former smoker $(\mathrm{n}, \%)$ & $93(37.7 \%)$ & $28(34.1 \%)$ & 65 (39.4\%) & \\
\hline Active smoker (n, \%) & $32(13.0 \%)$ & $10(12.2 \%)$ & $22(13.3 \%)$ & \\
\hline Stroke $(n, \%)$ & $11(4.5 \%)$ & $5(6.1 \%)$ & $6(3.6 \%)$ & 0.51 \\
\hline Diabetes (n, \%) & $55(22.3 \%)$ & $20(24.4 \%)$ & $35(21.2 \%)$ & 0.57 \\
\hline Type 1 diabetes & $13(23.6 \%)$ & $3(15.0 \%)$ & $10(28.6 \%)$ & \\
\hline Type 2 diabetes (with insulin) & $40(72.7 \%)$ & $17(85.0 \%)$ & $23(65.7 \%)$ & \\
\hline Type 2 diabetes (no insulin) & $2(3.6 \%)$ & $0(0.0 \%)$ & $2(5.7 \%)$ & \\
\hline History of coronary disease (n, \%) & $25(10.1 \%)$ & $9(11.0 \%)$ & $16(9.7 \%)$ & 0.75 \\
\hline Heart failure (n, \%) & $41(16.6 \%)$ & $17(20.7 \%)$ & $24(14.5 \%)$ & 0.22 \\
\hline Peripheral artery disease (n, \%) & $19(7.7 \%)$ & $4(4.9 \%)$ & $15(9.1 \%)$ & 0.24 \\
\hline Chronic obstructive pulmonary disease (n, \%) & $8(3.2 \%)$ & $5(6.1 \%)$ & $3(1.8 \%)$ & 0.12 \\
\hline Pre-transplant cancer $(\mathrm{n}, \%)$ & $10(4.0 \%)$ & $4(4.9 \%)$ & $6(3.6 \%)$ & 0.73 \\
\hline \multicolumn{5}{|l|}{ Causal nephropathy (n, \%) } \\
\hline Other & $25(10.1 \%)$ & $4(4.9 \%)$ & $21(12.7 \%)$ & 0.27 \\
\hline Chronic glomerulonephritis & $63(25.5 \%)$ & $21(25.6 \%)$ & $42(25.5 \%)$ & \\
\hline Toxic & $2(0.8 \%)$ & $1(1.2 \%)$ & $1(0.6 \%)$ & \\
\hline Diabetic nephropathy & $37(15.0 \%)$ & $10(12.2 \%)$ & $27(16.4 \%)$ & \\
\hline Vascular nephropathy & $20(8.1 \%)$ & $9(11.0 \%)$ & $11(6.7 \%)$ & \\
\hline Unknown & $37(15.0 \%)$ & $14(17.1 \%)$ & $23(13.9 \%)$ & \\
\hline Polycystic disease & $45(18.2 \%)$ & $13(15.9 \%)$ & $32(19.4 \%)$ & \\
\hline Nephrectomy & $2(0.8 \%)$ & $1(1.2 \%)$ & $1(0.6 \%)$ & \\
\hline Malformative uropathy & $12(4.9 \%)$ & $6(7.3 \%)$ & $6(3.6 \%)$ & \\
\hline Vasculitis & $4(1.6 \%)$ & $3(3.7 \%)$ & $1(0.6 \%)$ & \\
\hline Dialysis prior to transplantation $(\mathrm{n}, \%)$ & $209(84.6 \%)$ & $73(89.0 \%)$ & $136(82.4 \%)$ & 0.18 \\
\hline Peritoneal dialysis & $38(18.2 \%)$ & $15(20.5 \%)$ & $23(16.9 \%)$ & \\
\hline Hemodialysis & $171(81.8 \%)$ & $58(79.5 \%)$ & $113(83.1 \%)$ & \\
\hline Pre-transplant dialysis time (years) & $2.1 \pm 2.0$ & $2.1 \pm 2.0$ & $2.2 \pm 2.0$ & 0.73 \\
\hline \multicolumn{5}{|l|}{ TRANSPLANTATION DATA } \\
\hline Viral status CMV donor/recipient (n, \%) & & & & 0.51 \\
\hline $\mathrm{D}-/ \mathrm{R}-$ & $59(23.9 \%)$ & $22(26.8 \%)$ & $37(22.4 \%)$ & \\
\hline $\mathrm{D}-/ \mathrm{R}+$ & $57(23.1 \%)$ & $18(22.0 \%)$ & $39(23.6 \%)$ & \\
\hline $\mathrm{D}+/ \mathrm{R}-$ & $64(25.9 \%)$ & $17(20.7 \%)$ & $47(28.5 \%)$ & \\
\hline $\mathrm{D}+/ \mathrm{R}+$ & $67(27.1 \%)$ & $25(30.5 \%)$ & $42(25.5 \%)$ & \\
\hline Donor type $(\mathrm{n}, \%)$ & & & & 0.0008 \\
\hline Expanded criteria donor & $63(25.5 \%)$ & $17(20.7 \%)$ & $46(27.9 \%)$ & \\
\hline Standard criteria donor & $116(47.0 \%)$ & $52(63.4 \%)$ & $64(38.8 \%)$ & \\
\hline Living donor & $68(27.5 \%)$ & $13(15.9 \%)$ & $55(33.3 \%)$ & \\
\hline
\end{tabular}


Table 1 Baseline and follow-up data of patients according to the absence or presence of a reduced exposure to CNI (Continued)

\begin{tabular}{|c|c|c|c|c|}
\hline & Total $(n=247)$ & Controls $(n=82)$ & Reduced exposure to $\mathrm{CNI}(n=165)$ & $p$-value \\
\hline Cold ischemia time (hours) & $13.1 \pm 8.9$ & $14.5 \pm 8.0$ & $12.4 \pm 9.3$ & 0.023 \\
\hline \multicolumn{5}{|l|}{ HLA A-B-DR-DQ incompatibilities ( $n, \%)$} \\
\hline $0-3$ & $61(24.7 \%)$ & $17(20.7 \%)$ & $44(26.7 \%)$ & \multirow[t]{3}{*}{0.048} \\
\hline $4-5$ & $91(36.8 \%)$ & $39(47.6 \%)$ & $52(31.5 \%)$ & \\
\hline $6-8$ & $95(38.5 \%)$ & $26(31.7 \%)$ & $69(41.8 \%)$ & \\
\hline Induction treatment $(n, \%)$ & 235 (95.1\%) & 77 (93.9\%) & $158(95.8 \%)$ & \multirow[t]{3}{*}{0.54} \\
\hline Lymphocyte-depletive agent & $165(70.2 \%)$ & $56(72.7 \%)$ & 109 (69.0\%) & \\
\hline Anti-interleukin-2 receptor antibodies & $70(29.8 \%)$ & $21(27.3 \%)$ & $49(31.0 \%)$ & \\
\hline Mycofenolic acid cessation during follow-up & $28(11.3 \%)$ & $9(11.0 \%)$ & $19(11.5 \%)$ & 0.90 \\
\hline \multicolumn{5}{|l|}{ POST-TRANSPLANTATION EVENTS } \\
\hline Delayed graft function ( $n, \%)$ & $72(29.1 \%)$ & $30(36.6 \%)$ & $42(25.5 \%)$ & 0.070 \\
\hline Rejection (n, \%) & $42(17.0 \%)$ & $9(11.0 \%)$ & $33(20.0 \%)$ & \multirow[t]{4}{*}{0.075} \\
\hline$T$ cell mediated rejection & $40(16.2 \%)$ & $8(9.8 \%)$ & $32(19.4 \%)$ & \\
\hline Antibody mediated rejection & $3(1.2 \%)$ & $1(1.2 \%)$ & $2(1.2 \%)$ & \\
\hline Time to first rejection (years) & $0.5 \pm 1.0$ & $0.9 \pm 1.2$ & $0.4 \pm 0.9$ & \\
\hline Post-transplant cancer (n, \%) & $29(11.7 \%)$ & $9(11.0 \%)$ & $20(12.1 \%)$ & \multirow[t]{4}{*}{0.79} \\
\hline Skin cancer & $11(37.9 \%)$ & $2(22.2 \%)$ & $9(45.0 \%)$ & \\
\hline Hemopathy & $3(10.3 \%)$ & $1(11.1 \%)$ & $2(10.0 \%)$ & \\
\hline Solid cancer & $15(51.7 \%)$ & $6(66.7 \%)$ & $9(45.0 \%)$ & \\
\hline Time to post-transplant cancer (years) & $3.2 \pm 1.9$ & $4.0 \pm 2.0$ & $2.9 \pm 1.8$ & 0.15 \\
\hline Return in dialysis $(\mathrm{n}, \%)$ & $18(7.3 \%)$ & $3(3.7 \%)$ & $15(9.1 \%)$ & 0.12 \\
\hline Death with a functioning graft $(n, \%)$ & $22(8.9 \%)$ & $9(11.0 \%)$ & $13(7.9 \%)$ & 0.42 \\
\hline Graft failure from any cause including death $(\mathrm{n}, \%)$ & $40(16.2 \%)$ & $12(14.6 \%)$ & $28(17.0 \%)$ & 0.64 \\
\hline \multicolumn{5}{|l|}{ CNI Mean Absolute Deviation (\%) } \\
\hline Continuous & $19.9 \pm 9.6$ & $19.2 \pm 10.3$ & $20.3 \pm 9.3$ & 0.21 \\
\hline$<5 \%$ & $6(2.4 \%)$ & $2(2.4 \%)$ & $4(2.4 \%)$ & 1.00 \\
\hline$<15 \%$ & $87(35.2 \%)$ & $36(43.9 \%)$ & $51(30.9 \%)$ & 0.044 \\
\hline$>30 \%$ & $32(13.0 \%)$ & $12(14.6 \%)$ & $20(12.1 \%)$ & 0.58 \\
\hline$>50 \%$ & $2(0.8 \%)$ & $1(1.2 \%)$ & $1(0.6 \%)$ & 1.00 \\
\hline
\end{tabular}

$B M I$ Body Mass Index, DSA Donor Specific Antibody, $D-/ R$ - Donor negative/Recipient negative, $D-/ R+$ Donor negative/Recipient positive, $D+/ R$ - Donor positive/ Recipient negative, CNI Calcineurin inhibitors. Results with $p$ value less than $5 \%$ were emphasized using bold letters

During follow-up, 18 KTRs returned to dialysis and 22 patients died with a functioning graft. A reduced exposure to $\mathrm{CNI}$ tended to be associated with an increased risk of return to dialysis $(\mathrm{HR}=3.22(0.93-11.22), p=$ 0.066) (Table 3). There was no effect on patient survival or graft loss from any cause including death. Of note, there was no significant association between a reduced exposure to $\mathrm{CNI}$ and post-transplant cancer $(\mathrm{HR}=1.20$ $(0.55-2.62), p=0.64)$ (Table 3). Similar results were also found after exclusion of skin cancers.

\section{Discussion}

\section{Main findings}

In the present study, we demonstrate that even in a low-immunological risk population of kidney graft recipients, reduced exposure to CNI was associated with an increased risk of development of de novo DSA, known to be related to poor long-term graft outcomes. Long-term CNI exposure was assessed by taking into account different time intervals for the purpose of longitudinal pharmacological follow-up. Considering that the first detection of DSA frequently compels physicians to modify immunosuppressive treatment as well as the CNI target level, we deemed of value to take into account CNI exposure only in the period preceding DSA detection. Of note, a low exposure to CNI only tended in our cohort to be associated with increased risk of graft rejection, as well as increased risk of return to dialysis. 


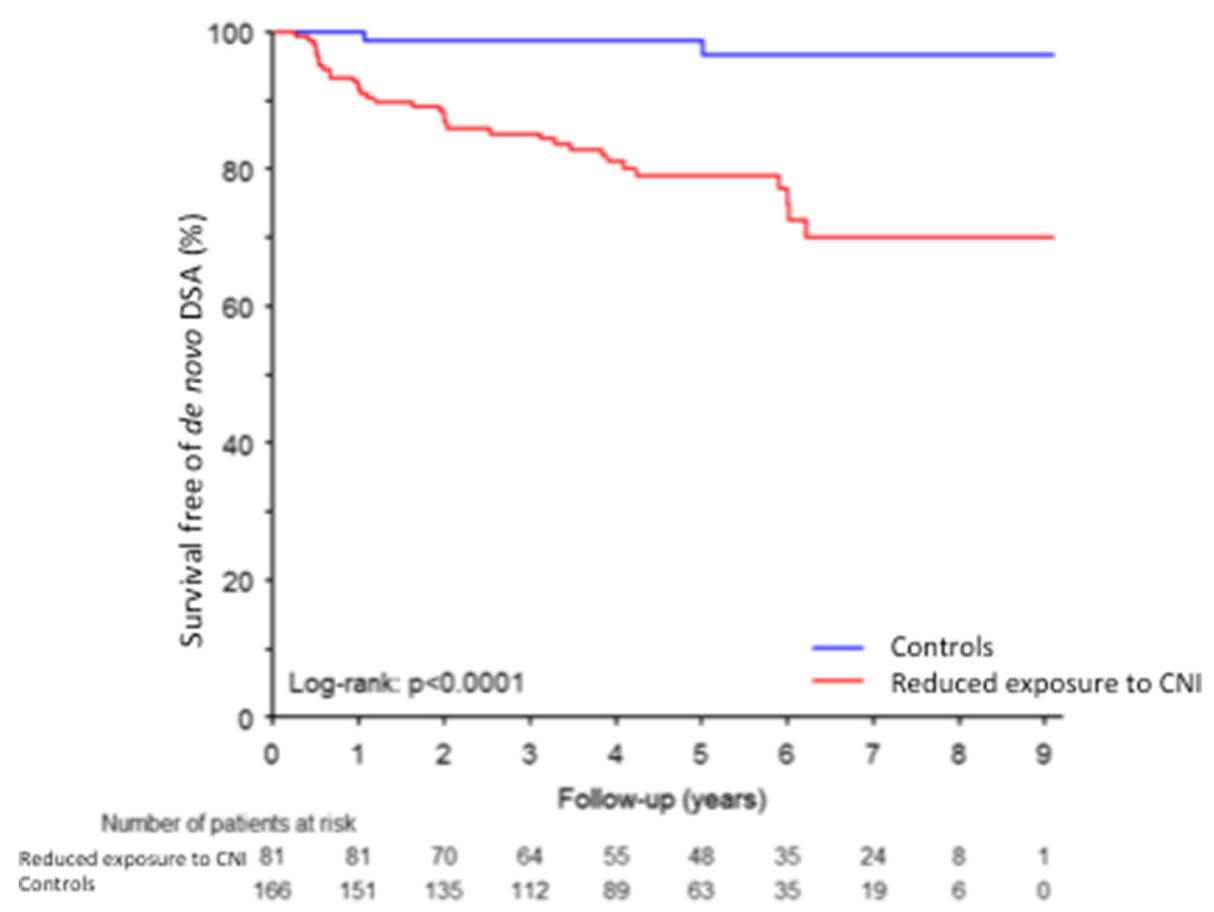

Fig. 4 De novo DSA detection according to the presence or the absence of a reduced exposure to CNI

\section{CNI minimization and graft or patient prognosis}

It is currently extremely difficult to draw definitive conclusions from the multiplicity of studies on CNI minimization given that strategies may vary in terms of: 1) the study population (baseline immunological risk), 2) CNI minimization strategy (withdrawn; long term maintenance with dose reduction; complete avoidance), 3) time of minimization (de novo; in case of graft function deterioration), 4) combination with an induction therapy, 5) combination with (or replacement with) maintenance therapy based on mycophenolic acid, mTOR inhibitors or belatacept. In a recent meta-analysis, Sawinski et al. assessed the impact on patient and allograft survival of four strategies of reduced-exposure to CNI (minimization, conversion, withdrawal and avoidance) [12]. The analysis of the 19 studies in which CNI minimization was associated with mycophenolic acid formulations reported reduced graft loss with this strategy, with a high level of evidence. In the most recent Cochrane meta-analysis (including randomized controlled trials (RCTs) with CNI withdrawal, tapering or low dose) [18], low dose CNI with induction regimens reduced acute rejection and graft loss, also in the short-term. The authors indicate that these conclusions must be tempered by the lack of long-term data in most of the studies, particularly with regards to chronic ABMR.

\section{Deleterious impact of DSA on graft prognosis}

Among sensitized patients, the deleterious impact on graft survival of preformed DSA is well established [19-21], with increased risk of ABMR and graft loss. Among non-sensitized patients, dnDSA may also develop after transplantation in $15 \%$ of kidney recipients [22-24], leading to increased risk of acute rejection $[23,25]$ and graft loss $[24,25]$. The incidence of acute rejection in kidney allograft recipients with dnDSA can reach $50 \%$, with up to $30 \%$ subclinical acute rejection [23-25]. ABMR represents a substantial proportion of these 50\% rejections [23-25], which constitutes the principal risk factor of graft loss [23-25]. dnDSA are also associated with subclinical histological lesions [26], which are an important determinant of graft survival [27, 28].

\section{CNI minimization and DSA development in the literature}

A few previous studies have assessed the impact of CNI minimization on dnDSA development. In a recent RCT, Gatault et al. [29] evaluated the efficacy and safety of two different doses of tacrolimus in KTRs between 4 and 12 months after transplantation. Stable steroid-free patients were randomized after 4 months: Group A had a 50\% reduction in tacrolimus dose with a targeted trough level > $3 \mathrm{ng} / \mathrm{mL}$ while group $\mathrm{B}$ had no change in tacrolimus dose (C0 7-12 ng/mL). The primary outcome was eGFR at 1 year. Estimated GFR was similar in both groups at 12 months, while dnDSA appeared only in group A (6 vs. 0 patients, $p=0.008$ ). The authors concluded that tacrolimus trough levels should be maintained $>7 \mathrm{ng} / \mathrm{mL}$ during the first year after transplantation in low-immunological risk, steroid-free patients receiving mycophenolic acid. 
Table 2 Baseline and follow-up data of patients according to the absence or presence of de novo DSA during follow-up

\begin{tabular}{|c|c|c|c|c|}
\hline & Population $(n=247)$ & No DSA $(n=208)$ & De novo DSA $(n=39)$ & $p$-value \\
\hline \multicolumn{5}{|l|}{ DEMOGRAPHICS } \\
\hline Age (years) & $50.9 \pm 14.1$ & $51.7 \pm 14.0$ & $46.6 \pm 13.8$ & 0.039 \\
\hline Male (n, \%) & $173(70.0 \%)$ & $142(68.3 \%)$ & $31(79.5 \%)$ & 0.16 \\
\hline $\mathrm{BMI}\left(\mathrm{kg} / \mathrm{m}^{2}\right)$ & $25.5 \pm 4.8$ & $25.3 \pm 4.9$ & $26.4 \pm 4.1$ & 0.16 \\
\hline \multicolumn{5}{|l|}{ COMORBIDITIES } \\
\hline No smoker (n, \%) & $122(49.4 \%)$ & $101(48.6 \%)$ & $21(53.8 \%)$ & 0.81 \\
\hline Former smoker (n, \%) & $93(37.7 \%)$ & $80(38.5 \%)$ & $13(33.3 \%)$ & \\
\hline Current smoker $(\mathrm{n}, \%)$ & $32(13.0 \%)$ & $27(13.0 \%)$ & $5(12.8 \%)$ & \\
\hline Stroke $(n, \%)$ & $11(4.5 \%)$ & $11(5.3 \%)$ & $0(0.0 \%)$ & 0.22 \\
\hline Diabetes (n, \%) & $55(22.3 \%)$ & $44(21.2 \%)$ & $11(28.2 \%)$ & 0.33 \\
\hline Type 1 diabetes & $13(23.6 \%)$ & $9(20.5 \%)$ & $4(36.4 \%)$ & \\
\hline Type 2 diabetes (with insulin) & $40(72.7 \%)$ & $34(77.3 \%)$ & $6(54.5 \%)$ & \\
\hline Type 2 diabetes (no insulin) & $2(3.6 \%)$ & $1(2.3 \%)$ & $1(9.1 \%)$ & \\
\hline History of coronary disease $(n, \%)$ & $25(10.1 \%)$ & $21(10.1 \%)$ & $4(10.3 \%)$ & 1.00 \\
\hline Heart failure $(n, \%)$ & $41(16.6 \%)$ & $33(15.9 \%)$ & $8(20.5 \%)$ & 0.47 \\
\hline Peripheral artery disease (n, \%) & $19(7.7 \%)$ & $16(7.7 \%)$ & $3(7.7 \%)$ & 1.00 \\
\hline Pre-transplant cancer (n, \%) & $10(4.0 \%)$ & $9(4.3 \%)$ & $1(2.6 \%)$ & 1.00 \\
\hline Causal nephropathy (n, \%) & & & & 0.24 \\
\hline Other & $25(10.1 \%)$ & $20(9.6 \%)$ & $5(12.8 \%)$ & \\
\hline Chronic glomerulonephritis & $63(25.5 \%)$ & $52(25.0 \%)$ & $11(28.2 \%)$ & \\
\hline Toxic & $2(0.8 \%)$ & $2(1.0 \%)$ & $0(0.0 \%)$ & \\
\hline Diabetic nephropathy & $37(15.0 \%)$ & $27(13.0 \%)$ & $10(25.6 \%)$ & \\
\hline Vascular nephropathy & $20(8.1 \%)$ & 19 (9.1\%) & $1(2.6 \%)$ & \\
\hline Unknown & $37(15.0 \%)$ & $35(16.8 \%)$ & $2(5.1 \%)$ & \\
\hline Polycystic disease & $45(18.2 \%)$ & $38(18.3 \%)$ & 7 (17.9\%) & \\
\hline Nephrectomy & $2(0.8 \%)$ & $1(0.5 \%)$ & $1(2.6 \%)$ & \\
\hline Malformative uropathy & $12(4.9 \%)$ & $10(4.8 \%)$ & $2(5.1 \%)$ & \\
\hline Vasculitis & $4(1.6 \%)$ & $4(1.9 \%)$ & $0(0.0 \%)$ & \\
\hline Dialysis prior to transplantation $(\mathrm{n}, \%)$ & $209(84.6 \%)$ & $174(83.7 \%)$ & 35 (89.7\%) & 0.33 \\
\hline Peritoneal dialysis & $38(18.2 \%)$ & $32(18.4 \%)$ & $6(17.1 \%)$ & \\
\hline Hemodialysis & $171(81.8 \%)$ & $142(81.6 \%)$ & $29(82.9 \%)$ & \\
\hline Pre-transplant dialysis time (years) & $2.1 \pm 2.0$ & $2.1 \pm 1.9$ & $2.2 \pm 2.1$ & 0.78 \\
\hline \multicolumn{5}{|l|}{ TRANSPLANTATION DATA } \\
\hline Viral status CMV donor/recipient (n, \%) & & & & 0.72 \\
\hline $\mathrm{D}-/ \mathrm{R}-$ & $59(23.9 \%)$ & $47(22.6 \%)$ & $12(30.8 \%)$ & \\
\hline $\mathrm{D}-/ \mathrm{R}+$ & $57(23.1 \%)$ & $48(23.1 \%)$ & $9(23.1 \%)$ & \\
\hline $\mathrm{D}+/ \mathrm{R}-$ & $64(25.9 \%)$ & $55(26.4 \%)$ & $9(23.1 \%)$ & \\
\hline $\mathrm{D}+/ \mathrm{R}+$ & $67(27.1 \%)$ & $58(27.9 \%)$ & $9(23.1 \%)$ & \\
\hline \multicolumn{5}{|l|}{ Donor type $(n, \%)$} \\
\hline Expanded criteria donor & $63(25.5 \%)$ & $55(26.4 \%)$ & $8(20.5 \%)$ & 0.72 \\
\hline Standard criteria donor & $116(47.0 \%)$ & $97(46.6 \%)$ & 19 (48.7\%) & \\
\hline Living donor & $68(27.5 \%)$ & $56(26.9 \%)$ & $12(30.8 \%)$ & \\
\hline Cold ischemia time (hours) & $13.1 \pm 8.9$ & $13.1 \pm 8.5$ & $12.8 \pm 10.9$ & 0.38 \\
\hline HLA A-B-DR-DQ incompatibilities (n, \%) & & & & 0.016 \\
\hline
\end{tabular}


Table 2 Baseline and follow-up data of patients according to the absence or presence of de novo DSA during follow-up (Continued)

\begin{tabular}{|c|c|c|c|c|}
\hline & Population $(n=247)$ & No DSA $(n=208)$ & De novo DSA $(n=39)$ & $p$-value \\
\hline $0-3$ & $61(24.7 \%)$ & $55(26.4 \%)$ & $6(15.4 \%)$ & \\
\hline $4-5$ & $91(36.8 \%)$ & $81(38.9 \%)$ & $10(25.6 \%)$ & \\
\hline $6-8$ & $95(38.5 \%)$ & $72(34.6 \%)$ & $23(59.0 \%)$ & \\
\hline Induction treatment $(\mathrm{n}, \%)$ & $235(95.1 \%)$ & $196(94.2 \%)$ & $39(100.0 \%)$ & 0.22 \\
\hline Lymphocyte-depletive agent & $165(70.2 \%)$ & $136(69.4 \%)$ & $29(74.4 \%)$ & \\
\hline Anti-interleukin-2 receptor antibodies & $70(29.8 \%)$ & $60(30.6 \%)$ & $10(25.6 \%)$ & \\
\hline Reduced exposure to CNI (n, \%) & $165(66.8 \%)$ & $129(62.0 \%)$ & $36(92.3 \%)$ & 0.0002 \\
\hline \multicolumn{5}{|l|}{ Mycophenolic acid cessation } \\
\hline During the entire follow-up & $28(11.3 \%)$ & $26(12.5 \%)$ & $2(5.1 \%)$ & 0.27 \\
\hline Before the first detection of DSA ${ }^{a}$ & $26(10.5 \%)$ & $26(12.5 \%)$ & $0(0.0 \%)$ & 0.019 \\
\hline \multicolumn{5}{|l|}{ POST-TRANSPLANTATION EVENTS } \\
\hline Delayed graft function (n, \%) & $72(29.1 \%)$ & $62(29.8 \%)$ & $10(25.6 \%)$ & 0.60 \\
\hline Rejection (n, \%) & $42(17.0 \%)$ & $30(14.4 \%)$ & $12(30.8 \%)$ & 0.013 \\
\hline $\mathrm{T}$ cell mediated rejection & $40(16.2 \%)$ & $30(14.4 \%)$ & $10(25.6 \%)$ & \\
\hline Antibody mediated rejection & $3(1.2 \%)$ & $0(0.0 \%)$ & $3(7.7 \%)$ & \\
\hline Time to first rejection (years) & $0.5 \pm 1.0$ & $0.3 \pm 0.6$ & $1.1 \pm 1.6$ & \\
\hline Post-transplant neoplasia (n, \%) & $29(11.7 \%)$ & $26(12.5 \%)$ & $3(7.7 \%)$ & 0.59 \\
\hline Skin cancer & $11(37.9 \%)$ & $11(42.3 \%)$ & $0(0.0 \%)$ & \\
\hline Hemopathy & $3(10.3 \%)$ & $3(11.5 \%)$ & $0(0.0 \%)$ & \\
\hline Solid cancer & $15(51.7 \%)$ & $12(46.2 \%)$ & $3(100.0 \%)$ & \\
\hline Time to post-transplant cancer (years) & $3.2 \pm 1.9$ & $3.1 \pm 1.9$ & $4.0 \pm 1.8$ & 0.44 \\
\hline Return in dialysis (n, \%) & $18(7.3 \%)$ & $10(4.8 \%)$ & $8(20.5 \%)$ & 0.003 \\
\hline Death with a functioning graft $(\mathrm{n}, \%)$ & $22(8.9 \%)$ & $19(9.1 \%)$ & $3(7.7 \%)$ & 1.00 \\
\hline Graft failure from any cause including death $(n, \%)$ & $40(16.2 \%)$ & $29(13.9 \%)$ & $11(28.2 \%)$ & 0.027 \\
\hline \multicolumn{5}{|l|}{ Mean Absolute Deviation (\%) } \\
\hline Continuous & $19.9 \pm 9.6$ & $19.8 \pm 9.3$ & $20.7 \pm 11.5$ & 0.99 \\
\hline$<5 \%$ & $6(2.4 \%)$ & $5(2.4 \%)$ & $1(2.6 \%)$ & 1.00 \\
\hline$<15 \%$ & $87(35.2 \%)$ & $76(36.5 \%)$ & $11(28.2 \%)$ & 0.32 \\
\hline$>30 \%$ & $32(13.0 \%)$ & $26(12.5 \%)$ & $6(15.4 \%)$ & 0.62 \\
\hline$>50 \%$ & $2(0.8 \%)$ & $1(0.5 \%)$ & $1(2.6 \%)$ & 0.29 \\
\hline
\end{tabular}

BMI Body Mass Index, DSA Donor Specific Antibody, $D-/ R$ - Donor negative/Recipient negative, $D-/ R+$ Donor negative/Recipient positive, $D+/ R$ - Donor positive/ Recipient negative, CNI Calcineurin inhibitors. Results with $p$ value less than $5 \%$ were emphasized using bold letters

a Number of patients (\%) with mycophenolic acid cessation during the follow-up restricted to the period before the first DSA detection in the group "de novo DSA" and during the entire follow-up in the group "no DSA"

In patients highly selected for a low immunological risk of rejection (long-term stable KTRs with no histological abnormality and absence of anti-HLA immunization), Dugast et al. conducted a double-blind RCT to analyze the benefits and risks of tacrolimus weaning [30]. Fifty-two patients were scheduled in each treatment arm, although only 10 patients were eligible and thus randomized. In the tacrolimus maintenance arm, graft function remains stable in all patients with no occurrence of graft rejection or anti-HLA immunization. In contrast, all the five patients of the placebo group developed either an acute graft rejection (humoral or not) or anti-HLA antibodies (DSA or not).
In a recent work, Béland et al. observed that among KTRs with dnDSA, higher CNI levels predicted better kidney graft survival, with a threshold of $5.3 \mathrm{ng} / \mathrm{mL}$ seemingly predictive of graft loss [16].

\section{Optimal trough levels of CNI / CNI target levels: Literature} data

The optimal CNI trough target level remains to be defined. The KDIGO guideline suggests that maintenance immunosuppressive medication should be administered at the lowest planned dose by $2-4$ months after transplantation if no rejection has occurred, although no target levels were proposed [31]. Over time, tacrolimus exposure levels have 


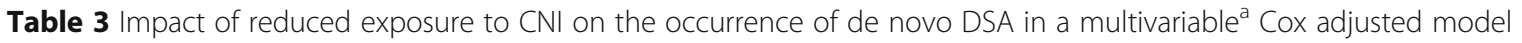

\begin{tabular}{|c|c|c|c|c|c|c|}
\hline \multirow[t]{2}{*}{ Event } & \multirow{2}{*}{$\begin{array}{l}\text { Reduced } \\
\text { exposure } \\
\text { to CNI }\end{array}$} & \multirow{2}{*}{$\begin{array}{l}\mathrm{Nb} \text { events/Nb } \\
\text { patients }\end{array}$} & \multicolumn{2}{|l|}{ Univariate model } & \multicolumn{2}{|l|}{ Multivariate model $^{a}$} \\
\hline & & & $\mathrm{HR}(\mathrm{Cl} 95 \%)$ & $\mathrm{p}$ & $\mathrm{HR}(\mathrm{Cl} 95 \%)$ & $p$ \\
\hline \multirow[t]{2}{*}{ First detection of one DSA with MFI > 1000} & No & $2 / 81(2.5 \%)$ & 1.00 & & 1.00 & \\
\hline & Yes & $35 / 166(21.1 \%)$ & $10.43(2.50-43.46)$ & 0.001 & $9.77(2.34-40.77)$ & 0.002 \\
\hline \multirow[t]{2}{*}{ First detection of one DSA with MFI > 6000} & No & $1 / 82(1.2 \%)$ & 1.00 & & 1.00 & \\
\hline & Yes & $22 / 165(13.3 \%)$ & $12.31(1.66-91.47)$ & 0.014 & $11.54(1.55-85.93)$ & 0.017 \\
\hline \multirow[t]{2}{*}{ First detection of one DSA with MFI > 10,000 } & No & $1 / 84(1.2 \%)$ & 1.00 & & 1.00 & \\
\hline & Yes & 16/163 (9.8\%) & $8.86(1.17-66.92)$ & 0.034 & $7.40(0.97-56.31)$ & 0.053 \\
\hline \multirow[t]{2}{*}{ First detection of DSA(s) with total MFI > 6000} & No & $1 / 82(1.2 \%)$ & 1.00 & & 1.00 & \\
\hline & Yes & 23/165 (13.9\%) & $12.81(1.73-94.97)$ & 0.013 & $12.02(1.62-89.25)$ & 0.015 \\
\hline \multirow[t]{2}{*}{ First detection of DSA(s) with total MFI > 10,000 } & No & $1 / 83(1.2 \%)$ & 1.00 & & 1.00 & \\
\hline & Yes & 19/164 (11.6\%) & $10.75(1.44-80.43)$ & 0.021 & $9.50(1.26-71.43)$ & 0.029 \\
\hline \multirow[t]{2}{*}{ First rejection } & No & $1 / 83(1.2 \%)$ & 1.00 & & 1.00 & \\
\hline & Yes & $11 / 164(6.7 \%)$ & $5.65(0.73-43.74)$ & 0.097 & $5.65(0.73-43.74)$ & 0.097 \\
\hline \multirow[t]{2}{*}{ Post-transplant neoplasia } & No & 10/88 (11.4\%) & 1.00 & & 1.00 & \\
\hline & Yes & 18/159 (11.3\%) & $1.16(0.53-2.52)$ & 0.71 & $1.20(0.55-2.62)$ & 0.64 \\
\hline \multirow[t]{2}{*}{ Post-transplant neoplasia (excluding skin neoplasia) } & No & $8 / 88(9.1 \%)$ & 1.00 & & 1.00 & \\
\hline & Yes & 10/159 (6.3\%) & $0.75(0.30-1.91)$ & 0.55 & $0.75(0.30-1.91)$ & 0.55 \\
\hline \multirow[t]{2}{*}{ Return in dialysis } & No & $3 / 87$ (3.4\%) & 1.00 & & 1.00 & \\
\hline & Yes & 15/160 (9.4\%) & $3.22(0.93-11.22)$ & 0.066 & $3.22(0.93-11.22)$ & 0.066 \\
\hline \multirow[t]{2}{*}{ Patient survival } & No & 9/87 (10.3\%) & 1.00 & & 1.00 & \\
\hline & Yes & 13/160 (8.1\%) & $1.01(0.43-2.38)$ & 0.97 & $1.03(0.44-2.43)$ & 0.94 \\
\hline \multirow[t]{2}{*}{ Graft survival } & No & 12/87 (13.8\%) & 1.00 & & 1.00 & \\
\hline & Yes & 28/160 (17.5\%) & $1.57(0.80-3.11)$ & 0.19 & $1.64(0.82-3.28)$ & 0.16 \\
\hline
\end{tabular}

DSA: Donor Specific Antibody, MFI Mean Fluorescence Intensity. Results with $p$ value less than $5 \%$ were emphasized using bold letters

aMultivariable analyses were performed using iterative backward selection, by forcing "reduced exposure to CNI" in the Cox model, with the following variables as candidate covariates: number of HLA mismatches, donor type (living, deceased -standard or extended criteria-), age and gender of the recipient, mycofenolic acid cessation, delayed graft function and induction therapy

declined [31]. In more recent RCTs, the standard tacrolimus trough level 6 months after transplantation was defined between 5 and $10 \mathrm{ng} / \mathrm{mL}$ [32] or $6-9 \mathrm{ng} / \mathrm{mL}$ [33] although lower exposure ranges have been tested [34, 35]. In the present study, we consequently endeavored to encompass the latter with the term "international targets" comprised of a tacrolimus trough level between 6 and $8 \mathrm{ng} / \mathrm{mL}$ after 6 months and between 5 and $8 \mathrm{ng} / \mathrm{mL}$ after 12 months.

Certain authors have attempted to combine the data [36] of three large RCTs (the FDCC [37], Elite-Symphony [34] and OptiCept [38] trials) in order to determine the optimal tacrolimus $\mathrm{C} 0$ to prevent acute rejection during the first year of kidney transplantation. In general, these patients had a low-to-medium immunological risk. In the FDCC study, the mean tacrolimus C0 was $10-14 \mathrm{ng} / \mathrm{mL}$ in the first month, and tapered gradually thereafter. In the Elite-Symphony study, tacrolimus trough levels were 3-7 $\mathrm{ng} / \mathrm{mL}$ during the study period. In the OptiCept trial, the tacrolimus trough levels were $8-12 \mathrm{ng} / \mathrm{mL}$ during the first month, 4-6 or 8-10 ng/mL until the end of the third months, and 3-5 or $6-8 \mathrm{ng} / \mathrm{mL}$ from the fourth month thereafter, according to the randomization groups (reduced or standard CNI dosing). Despite this pooled analysis, the authors failed to find any significant correlations between tacrolimus trough levels and the incidence of acute rejection at the different time points.

In a recent study reporting on the pooled data [39] of four RCTs [40-43] $(n=528)$ in which patients received reduced tacrolimus dosing combined with mycofenolic acid, the authors concluded that tacrolimus levels < $4 \mathrm{ng} / \mathrm{mL}$ should be avoided during the first 12 months post-transplantation when tacrolimus is used in combination with fixed-dose mycofenolic acid with or without corticosteroids and induction therapy.

\section{Study limitations}

Certain limitations of this study should be acknowledged, the first of which being its observational single-center design. Second, protocol biopsies were not performed, nor was a biopsy systematically performed in instances of dnDSA detection. Consequently, the low number of ABMR should be taken with caution. Third, although IPV was 
used herein as a proxy of patient adherence [44], it remains quite difficult to distinguish true minimization from non-adherence. Nevertheless, patients with $>50 \%$ non available trough levels were excluded from the analysis, with is also a well-known marker of non-adherence among KTRs. Consequently, it would appear reasonable to assume that the proportion of non-adherent patients was low in this study. Moreover, we discuss in this study the impact of reduced exposure to $\mathrm{CNI}$, irrespective of its cause. Of note only 7 patients were excluded from study population because they had $\geq 50 \%$ of CNI trough levels non-available. And among these patients, only one developed dnDSA during follow-up. Due to this very small number of patients, it seems unreasonable to add a third group "non-adherence" in this study. Indeed, the addition of this third group is unlikely to allow us drawing reliable conclusion. Fourth, certain other factors potentially contributing to dnDSA development were not taking into account in this study, namely post-transplant pregnancies and transfusions [45]. Finally, while multivariable analyses were adjusted according to induction treatment and mycofenolic acid cessation during follow-up, mycofenolic acid dosage (area under curve) was not taken into account.

\section{Clinical implications}

In kidney graft recipients with low immunological risk, it is generally acknowledged that immunosuppressive treatment should be minimized given the low risk of graft rejection, and thus avoid exposing these patients to an accrued risk of neoplastic or infectious complications, as well as nephrotoxicity. As a result, clinicians frequently target low CNI trough levels in these cases. However, it should be kept in mind that such strategy is not without challenges in terms of risk of dnDSA development even in non-sensitized patients. At the very least, patients should be carefully monitored for DSA detection, in order to readjust treatment. Nevertheless, a low exposure to CNI only tended in our cohort to be associated with increased risk of graft rejection, as well as increased risk of return to dialysis. Although this absence of significant associations may be partly due to the size of our cohort, it also suggests that conflicting effects of CNI minimization might result in overall neutral effect. Despite an increased risk of dnDSA development, CNI minimization may well be beneficial for long-term graft prognosis by the way of nephrotoxicity avoidance among low-immunological risk patients [12, 18]. There are promising alternative strategies, such as the use of belatacept, which is a nonnephrotoxic drug, with no reported increased risk of DSA development [46]. The association of low-dose CNI with mTOR inhibitors could also be interesting, and has to be evaluated in regards to the risk of dnDSA development. In the recent multicenter non-inferiority trial
TRANSFORM [47], 2037 de novo kidney transplant recipients were randomized to receive, everolimus with reduced-exposure CNI or mycophenolic acid with standard-exposure CNI. DnDSA incidence at 12 months and ABMR rate did not differ between the two arms. Long-term results of the studies TRANSFORM [47] and ATHENA [48] will provide useful data.

\section{Conclusions}

Even in a low-immunological risk population, reduced exposure to $\mathrm{CNI}$ is associated with increased risk of dnDSA. Benefits and risks of under-immunosuppression must be carefully evaluated before deciding on CNI minimization.

\section{Abbreviations}

ABMR: Acute antibody-mediated rejection; C0: Trough level; CNI: Calcineurin inhibitors; dnDSA: De novo Donor Specific Antibodies; ECD: Expanded criteria donors; eGFR: Estimated Glomerular Filtration Rate; HLA: Human Leukocyte Antigen; HR: Hazard Ratio; IPV: Intra-patient variability; KTR: Kidney transplant recipients; MAD\%: Mean absolute deviation percent; RCT: Randomized Controlled Trial; SCD: Standard criteria donors

\section{Availability of data and materials}

The datasets used and/or analysed during the current study are available from the corresponding author on reasonable request.

\section{Authors' contributions}

SG: participated in research design, in the collection of the data, in the writing of the manuscript, in data analysis and data interpretation. JS: participated in research design, in the collection of the data, in the writing of the manuscript, in data interpretation. NG: participated in research design, in the reviewing of the manuscript, in data analysis and data interpretation. KD: participated in research design, in the reviewing of the manuscript, in data analysis and data interpretation. HB: participated in the collection of the data, in the reviewing of the manuscript, and data interpretation. NG: participated in the collection of the data, in the reviewing of the manuscript. ML: participated in the collection of the data, in the reviewing of the manuscript, and data interpretation. MK: participated in the collection of the data, in the reviewing of the manuscript, and in data interpretation. LF: participated in research design, in the reviewing of the manuscript, and data interpretation. AA: participated in research design, in the collection of the data, in the reviewing of the manuscript, in data analysis and data interpretation. All authors read and approved the final manuscript.

\section{Ethics approval and consent to participate}

Data were extracted from the prospective French database of transplanted patients DIVAT (computerized and VAlidated data in Transplantation). The "Comité National de I'Informatique et des Libertés" approved the study (CNIL no. 891735) and written informed consent was obtained from all participants.

\section{Consent for publication}

"Not applicable".

\section{Competing interests}

The authors declare that they have no competing interests.

\section{Publisher's Note}

Springer Nature remains neutral with regard to jurisdictional claims in published maps and institutional affiliations. 


\section{Author details}

${ }^{1}$ Service de Néphrologie et Transplantation rénale, CHRU Nancy Brabois, Vandoeuvre-les-, Nancy, France. ${ }^{2}$ INSERM, Centre d'Investigations Cliniques Plurithématique 1433, Université de Lorraine, CHRU de Nancy and F-CRIN INI-CRCT, Nancy, France. ${ }^{3}$ Service d'Anatomie pathologique, CHRU Nancy Brabois, Vandœuvre-lès-Nancy, France. ${ }^{4}$ Service de

Pharmacologie-Toxicologie, CHRU Nancy Brabois, Vandœuvre-lès-Nancy, France. ${ }^{5}$ Laboratoire d'Histocompatibilité, CHRU Nancy Brabois, Vandoeuvre-lès-Nancy, France.

Received: 19 April 2018 Accepted: 24 August 2018 Published online: 15 September 2018

\section{References}

1. Naesens M, Kuypers DR, Sarwal M. Calcineurin inhibitor nephrotoxicity. Clinical journal of the American Society of Nephrology : CJASN. 2009;4(2):481-508.

2. Gaston RS. Chronic calcineurin inhibitor nephrotoxicity: reflections on an evolving paradigm. Clinical journal of the American Society of Nephrology : CJASN. 2009:4(12):2029-34.

3. Matas AJ. Chronic progressive calcineurin nephrotoxicity: an overstated concept. Am J Transplant Off J Am Soc Transplant Am Soc Transplant Surg. 2011;11(4):687-92.

4. Einecke G, Sis B, Reeve J, et al. Antibody-mediated microcirculation injury is the major cause of late kidney transplant failure. Am J Transplant Off J Am Soc Transplant Am Soc Transplant Surg. 2009;9(11):2520-31.

5. Gaston RS, Cecka JM, Kasiske BL, et al. Evidence for antibody-mediated injury as a major determinant of late kidney allograft failure. Transplantation. 2010;90(1):68-74.

6. Loupy A, Hill GS, Jordan SC. The impact of donor-specific anti-HLA antibodies on late kidney allograft failure. Nat Rev Nephrol. 2012;8(6):348-57.

7. Gourishankar S, Leduc R, Connett J, et al. Pathological and clinical characterization of the 'troubled transplant': data from the DeKAF study. Am J Transplant Off J Am Soc Transplant Am Soc Transplant Surg. 2010;10(2):324-30.

8. Bamoulid J, Staeck O, Halleck F, et al. The need for minimization strategies: current problems of immunosuppression. Transplant international : official journal of the European Society for Organ Transplantation. 2015;28(8):891-900.

9. Prashar $\mathrm{R}$, Venkat KK. Immunosuppression minimization and avoidance protocols: when less is not more. Adv Chronic Kidney Dis. 2016;23(5): 295-300.

10. Sharif A, Shabir S, Chand S, Cockwell P, Ball S, Borrows R. Meta-analysis of calcineurin-inhibitor-sparing regimens in kidney transplantation. Journal of the American Society of Nephrology : JASN. 2011;22(11):2107-18.

11. Moore J, Middleton L, Cockwell $P$, et al. Calcineurin inhibitor sparing with mycophenolate in kidney transplantation: a systematic review and metaanalysis. Transplantation. 2009;87(4):591-605.

12. Sawinski D, Trofe-Clark J, Leas B, et al. Calcineurin inhibitor minimization, conversion, withdrawal, and avoidance strategies in renal transplantation: a systematic review and meta-analysis. Am J Transplant Off J Am Soc Transplant Am Soc Transplant Surg. 2016;16(7):2117-38.

13. Clinical Guidelines for Transpant Medications. 2018. http://www.transplant.bc ca/Documents/Health\%20Professionals/Clinical\%20guidelines/Clinical\%20 Guidelines\%20for\%20Transplant\%20Medications\%20-\%20June\%202018.pdf.

14. Schiff J, Cole E, Cantarovich M. Therapeutic monitoring of calcineurin inhibitors for the nephrologist. Clinical journal of the American Society of Nephrology: CJASN. 2007;2(2):374-84.

15. Wallemacq $P$, Armstrong W, Brunet $M$, et al. Opportunities to optimize tacrolimus therapy in solid organ transplantation: report of the European consensus conference. Ther Drug Monit. 2009;31(2):139-52.

16. Beland MA, Lapointe I, Noel R, et al. Higher calcineurin inhibitor levels predict better kidney graft survival in patients with de novo donor-specific anti-HLA antibodies: a cohort study. Transplant international : official journal of the European Society for Organ Transplantation. 2017;30(5):502-9.

17. Shuker N, van Gelder T, Hesselink DA. Intra-patient variability in tacrolimus exposure: causes, consequences for clinical management. Transplant Rev (Orlando). 2015;29(2):78-84.

18. Karpe KM, Talaulikar GS, Walters GD. Calcineurin inhibitor withdrawal or tapering for kidney transplant recipients. Cochrane Database Syst Rev. 2017; 7:CD006750.

19. Lefaucheur C, Loupy A, Hill GS, et al. Preexisting donor-specific HLA antibodies predict outcome in kidney transplantation. Journal of the American Society of Nephrology : JASN. 2010;21(8):1398-406.
20. Mohan S, Palanisamy A, Tsapepas D, et al. Donor-specific antibodies adversely affect kidney allograft outcomes. Journal of the American Society of Nephrology : JASN. 2012;23(12):2061-71.

21. Vo AA, Peng A, Toyoda $M$, et al. Use of intravenous immune globulin and rituximab for desensitization of highly HLA-sensitized patients awaiting kidney transplantation. Transplantation. 2010;89(9):1095-102.

22. Hidalgo LG, Campbell PM, Sis B, et al. De novo donor-specific antibody at the time of kidney transplant biopsy associates with microvascular pathology and late graft failure. Am J Transplant Off J Am Soc Transplant Am Soc Transplant Surg. 2009;9(11):2532-41.

23. Heilman RL, Nijim A, Desmarteau YM, et al. De novo donor-specific human leukocyte antigen antibodies early after kidney transplantation. Transplantation. 2014;98(12):1310-5.

24. Cooper JE, Gralla J, Cagle L, Goldberg R, Chan L, Wiseman AC. Inferior kidney allograft outcomes in patients with de novo donor-specific antibodies are due to acute rejection episodes. Transplantation. 201 1;91(10):1103-9.

25. Devos JM, Gaber AO, Teeter LD, et al. Intermediate-term graft loss after renal transplantation is associated with both donor-specific antibody and acute rejection. Transplantation. 2014;97(5):534-40.

26. Wiebe C, Gibson IW, Blydt-Hansen TD, et al. Evolution and clinical pathologic correlations of de novo donor-specific HLA antibody post kidney transplant. Am J Transplant Off J Am Soc Transplant Am Soc Transplant Surg. 2012;12(5):1157-67.

27. Moreso F, Ibernon M, Goma M, et al. Subclinical rejection associated with chronic allograft nephropathy in protocol biopsies as a risk factor for late graft loss. Am J Transplant Off J Am Soc Transplant Am Soc Transplant Surg. 2006;6(4):747-52.

28. Moreso F, Carrera M, Goma M, et al. Early subclinical rejection as a risk factor for late chronic humoral rejection. Transplantation. 2012;93(1):41-6.

29. Gatault P, Kamar N, Buchler M, et al. Reduction of extended-release tacrolimus dose in low-immunological-risk kidney transplant recipients increases risk of rejection and appearance of donor-specific antibodies: a randomized study. Am J Transplant Off J Am Soc Transplant Am Soc Transplant Surg. 2017;17(5):1370-9.

30. Dugast E, Soulillou JP, Foucher Y, et al. Failure of Calcineurin inhibitor (tacrolimus) weaning randomized trial in long-term stable kidney transplant recipients. Am J Transplant Off J Am Soc Transplant Am Soc Transplant Surg. 2016;16(11):3255-61.

31. KDIGO clinical practice guideline for the care of kidney transplant recipients. Am J Transplant : official journal of the American Society of Transplantation and the American Society of Transplant Surgeons. 2009;9 Suppl 3:S1-155.

32. Ferguson R, Grinyo J, Vincenti F, et al. Immunosuppression with belataceptbased, corticosteroid-avoiding regimens in de novo kidney transplant recipients. Am J Transplant Off J Am Soc Transplant Am Soc Transplant Surg. 2011;11(1):66-76.

33. Bolin P Jr, Shihab FS, Mulloy L, et al. Optimizing tacrolimus therapy in the maintenance of renal allografts: 12-month results. Transplantation. 2008; 86(1):88-95.

34. Ekberg H, Tedesco-Silva H, Demirbas A, et al. Reduced exposure to calcineurin inhibitors in renal transplantation. N Engl J Med. 2007;357(25):2562-75.

35. Kamar N, Rostaing L, Cassuto E, et al. A multicenter, randomized trial of increased mycophenolic acid dose using enteric-coated mycophenolate sodium with reduced tacrolimus exposure in maintenance kidney transplant recipients. Clin Nephrol. 2012;77(2):126-36.

36. Bouamar R, Shuker N, Hesselink DA, et al. Tacrolimus predose concentrations do not predict the risk of acute rejection after renal transplantation: a pooled analysis from three randomized-controlled clinical trials(dagger). Am J Transplant Off J Am Soc Transplant Am Soc Transplant Surg. 2013;13(5):1253-61

37. van Gelder T, Silva HT, de Fijter JW, et al. Comparing mycophenolate mofetil regimens for de novo renal transplant recipients: the fixed-dose concentration-controlled trial. Transplantation. 2008;86(8):1043-51.

38. Gaston RS, Kaplan B, Shah T, et al. Fixed- or controlled-dose mycophenolate mofetil with standard- or reduced-dose calcineurin inhibitors: the Opticept trial. Am J Transplant Off J Am Soc Transplant Am Soc Transplant Surg. 2009;9(7):1607-19.

39. Gaynor JJ, Ciancio G, Guerra G, et al. Lower tacrolimus trough levels are associated with subsequently higher acute rejection risk during the first 12 months after kidney transplantation. Transplant international : official journal of the European Society for Organ Transplantation. 2016;29(2):216-26.

40. Ciancio G, Burke GW, Gaynor JJ, et al. A randomized long-term trial of tacrolimus/sirolimus versus tacrolimus/mycophenolate mofetil versus 
cyclosporine (NEORAL)/sirolimus in renal transplantation. II. Survival, function, and protocol compliance at 1 year. Transplantation. 2004;77(2):252-8.

41. Ciancio G, Burke GW, Gaynor JJ, et al. A randomized trial of three renal transplant induction antibodies: early comparison of tacrolimus, mycophenolate mofetil, and steroid dosing, and newer immunemonitoring. Transplantation. 2005;80(4):457-65.

42. Ciancio G, Gaynor JJ, Roth D, et al. Randomized trial of thymoglobulin versus alemtuzumab (with lower dose maintenance immunosuppression) versus daclizumab in living donor renal transplantation. Transplant Proc. 2010;42(9):3503-6.

43. Ciancio G, Burke GW, Gaynor JJ, et al. Randomized trial of mycophenolate mofetil versus enteric-coated mycophenolate sodium in primary renal transplant recipients given tacrolimus and daclizumab/thymoglobulin: one year follow-up. Transplantation. 2008;86(1):67-74.

44. Neuberger JM, Bechstein WO, Kuypers DR, et al. Practical recommendations for long-term Management of Modifiable Risks in kidney and liver transplant recipients: a guidance report and clinical checklist by the consensus on managing modifiable risk in transplantation (COMMIT) group. Transplantation. 2017;101(4S Suppl 2):S1-S56.

45. Ferrandiz I, Congy-Jolivet N, Del Bello A, et al. Impact of early blood transfusion after kidney transplantation on the incidence of donor-specific anti-HLA antibodies. Am J Transplant Off J Am Soc Transplant Am Soc Transplant Surg. 2016;16(9):2661-9.

46. Bray RA, Gebel HM, Townsend R, et al. De novo donor-specific antibodies in belatacept-treated vs cyclosporine-treated kidney-transplant recipients: post hoc analyses of the randomized phase III BENEFIT and BENEFIT-EXT studies. Am J Transplant Off J Am Soc Transplant Am Soc Transplant Surg. 2018; 18(7):1783-9.

47. Pascual J, Berger SP, Witzke O, et al. Everolimus with reduced Calcineurin inhibitor exposure in renal transplantation. Journal of the American Society of Nephrology : JASN. 2018;29(7):1979-91.

48. Sommerer C, Suwelack B, Dragun D, et al. Design and rationale of the ATHENA study--a 12-month, multicentre, prospective study evaluating the outcomes of a de novo everolimus-based regimen in combination with reduced cyclosporine or tacrolimus versus a standard regimen in kidney transplant patients: study protocol for a randomised controlled trial. Trials. 2016;17:92.

Ready to submit your research? Choose BMC and benefit from:

- fast, convenient online submission

- thorough peer review by experienced researchers in your field

- rapid publication on acceptance

- support for research data, including large and complex data types

- gold Open Access which fosters wider collaboration and increased citations

- maximum visibility for your research: over $100 \mathrm{M}$ website views per year

At $\mathrm{BMC}$, research is always in progress.

Learn more biomedcentral.com/submissions 